\title{
Unusual features in the conjunctiva and cornea of the normal guinea-pig: clinical and histological studies
}

\author{
R. ST. C. DWYER, S. DAROUGAR, AND MARJORIE A. MONNICKENDAM \\ From the Subdepartment of Virology, Institute of Ophthalmology, Judd Street, London WC1H $9 Q S$
}

SUMmARY Clinical and histological studies of the outer eyes of newborn and adult female guineapigs were carried out together with histological studies of fetal eyes. Fine superficial corneal vessels, extending from the limbus, were seen in most newborn and adult eyes and were also present in histological preparations of fetal eyes. These vessels were therefore considered to be features of the normal guinea-pig eye. Masses of tissue composed of lymphoid cells, which were often organised into germinal centres, were found in the fornices of newborn and adult eyes. Smaller accumulations of lymphoid cells were found in fetal eyes, and this lymphoid tissue was therefore also considered to be a normal feature of the guinea-pig eye. In adult eyes mild but short-lived oedema or hyperaemia of the palpebral conjunctiva was quite common. There were no differences in the amounts of conjunctival cellular infiltration in these eyes compared with normal eyes, and these inflammatory changes were therefore not considered to be significant.

Although the guinea-pig conjunctiva and cornea have often been used in studies of immune responses and infections, ${ }^{1-5}$ there has been no adequate description of the outer eye of the normal guinea-pig. In our studies using considerable numbers of guinea-pigs we have observed features in the normal eye which could be mistaken for pathological changes and which have not been described by other investigators.

In this paper we describe clinical and histological findings in the conjunctivae and corneas of normal eyes from guinea-pigs of various ages.

\section{Materials and methods}

Animals. Adult female albino guinea-pigs of the Dunkin-Hartley strain, weighing between 250 and $500 \mathrm{~g}$, were used. They were obtained from 10 suppliers accredited by the Medical Research Council. Fetal guinea-pigs were obtained by caesarian section near to full term; newborn animals were produced in our own animal house.

Clinical examination. The methods of clinical examination of the conjunctiva and cornea, and scoring of inflammatory changes have been described previously. ${ }^{6}$ In addition, corneal vessels were graded 0 to 3 as follows: vessels extending from the limbus into the first third of the cornea were graded as 1 , into the second third as 2 , and into the centre as 3 .

Histological examination. Eyes were removed as an en-bloc dissection of eyelids, conjunctival sac, and globe and were fixed in a modified picric acid fixative. ${ }^{7}$ They were embedded in paraffin wax, and 6 $\mu \mathrm{m}$ sections were stained with celestin blue, haemalum, and eosin, or methyl-green pyronin.

Inflammatory cells under the conjunctival epithelium were counted at a magnification of $\times 400$ with the aid of a rectangular grid. This covered an area of $0.013 \mathrm{~mm}^{2}$. Cells were counted at 8 sites (Fig. 1) and the mean counts at corresponding sites (e.g., 1 and 8 ) calculated.

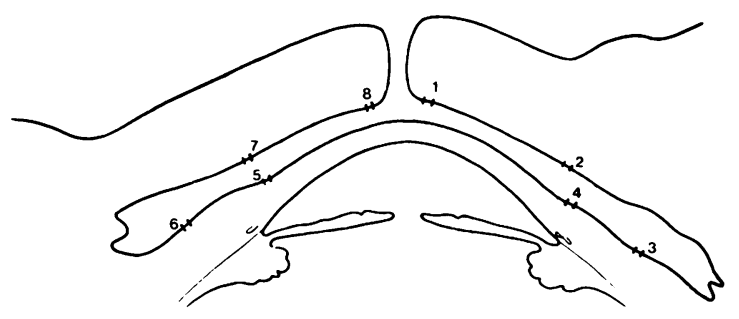

Fig. 1 Position of sites for counting cells. Nos. 1, 8 palpebral conjunctiva near lid margin; 2, 7 palpebral conjunctiva (middle); 3, 6 bulbar conjunctiva (middle); 4, 5 limbus. 
Table 1 Presence and intensity of inflammatory changes in the palpebral conjunctiva in adult female guinea-pigs

\begin{tabular}{|c|c|c|c|c|}
\hline Signs & Region & Grade 1 & Grade 2 & Total ${ }^{*}$ \\
\hline Hyperaemia & $\begin{array}{l}\text { Upper } \\
\text { Lower }\end{array}$ & $\begin{array}{l}89(12 \cdot 6 \%) \\
74(10 \cdot 5 \%)\end{array}$ & $\begin{array}{l}7(1.0 \%) \\
5(0.7 \%)\end{array}$ & $\begin{array}{l}96(13 \cdot 6 \%) \\
79(11 \cdot 2 \%)\end{array}$ \\
\hline Oedema & $\begin{array}{l}\text { Upper } \\
\text { Lower }\end{array}$ & $\begin{array}{r}144(20 \cdot 5 \%) \\
85(12 \cdot 1 \%)\end{array}$ & $\begin{array}{r}12(1.7 \%) \\
3(0.4 \%)\end{array}$ & $\begin{array}{r}156(22 \cdot 2 \%) \\
88(12 \cdot 5 \%)\end{array}$ \\
\hline Linear scars & $\begin{array}{l}\text { Upper } \\
\text { Lower }\end{array}$ & $\begin{array}{l}0 \\
3(0 \cdot 4 \%)\end{array}$ & $\begin{array}{l}1(0 \cdot 1 \%) \\
2(0.3 \%)\end{array}$ & $\begin{array}{l}1(0 \cdot 1 \%) \\
5(0.7 \%)\end{array}$ \\
\hline
\end{tabular}

${ }^{*}$ Total eyes examined $=704$.

\section{Results}

\section{CLINICAL FINDINGS}

\section{Adults}

The eyes of 352 apparently normal, healthy adult female guinea-pigs were examined.

Watery or mucoid exudate was seen in $154(22 \%)$ and $96(14 \%)$ eyes respectively, while purulent exudate was observed in only 3 eyes. These 3 eyes had other signs of inflammation, and in one a large plant seed was lodged in the lower conjunctival sac.

At the lid margin erythema was observed in 16 (2\%) eyes, and all these had other signs of ocular inflammation. Oedema was found in $8(1 \%)$ eyes; of these eyes 4 also had erythema and the remaining 4 had no other signs. One animal had a scar at the lid margin, and another had entropion and a completely vascularised cornea.

Clinical signs were most commonly found in the palpebral conjunctiva. Oedema was the most common sign, and both hyperaemia and oedema were found in the upper palpebral conjunctiva more often than in the lower (Table 1). Scars were found in 8 animals. In addition to the linear scars listed in Table 1 , one animal had a diffuse scar, and 2 other animals had smaller areas of fibrotic tissue.

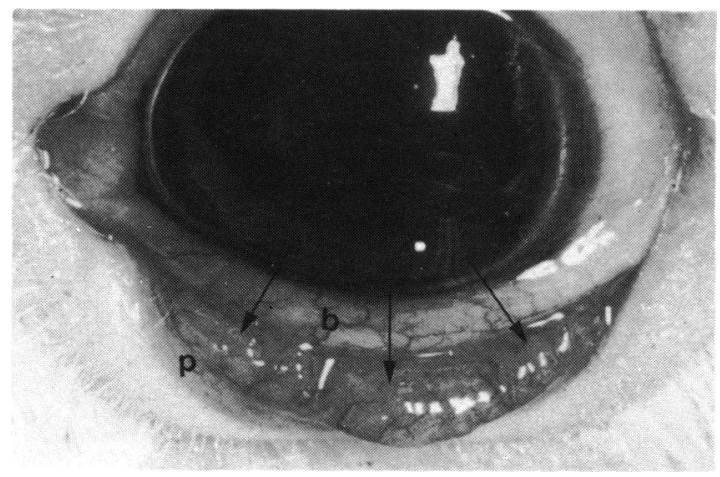

Fig. 2 Adult guinea-pig eye with lower lid everted to show protuberances (arrows), palpebral conjunctiva (p), and bulbar conjunctiva (b).
Small protuberances were observed in the upper and lower fornices of both eyes in almost all animals. In some these protuberances consisted of a single, large mass, while in others several smaller masses, contiguous but more or less discrete, were present (Fig. 2).

In the bulbar conjunctiva oedema and hyperaemia were found in $73(10 \%)$ and $19(3 \%)$ eyes respectively and were usually associated with signs in other areas. Slight limbal oedema was seen in $39(6 \%)$ eyes and was also found in association with other signs.

Fine superficial stromal blood vessels, extending from the limbus into the cornea, were observed in $90 \%$ of adult animals. Grade 1 or 2 vessels were most commonly found, usually in the complete absence of ocular inflammation (Fig. 3). Grade 3 vessels were seen in $15(2 \%)$ eyes.

Three of the adults had corneal abnormalities. One had a completely vascularised cornea, which was associated with entropion. A second had central stromal keratitis and ulceration in one eye, with blood vessels extending from the limbus to the edge of the ulcer, but no clinical signs in other areas; and the third had a moderate diffuse epithelial keratitis with mild uveitis and mild oedema in one eye.

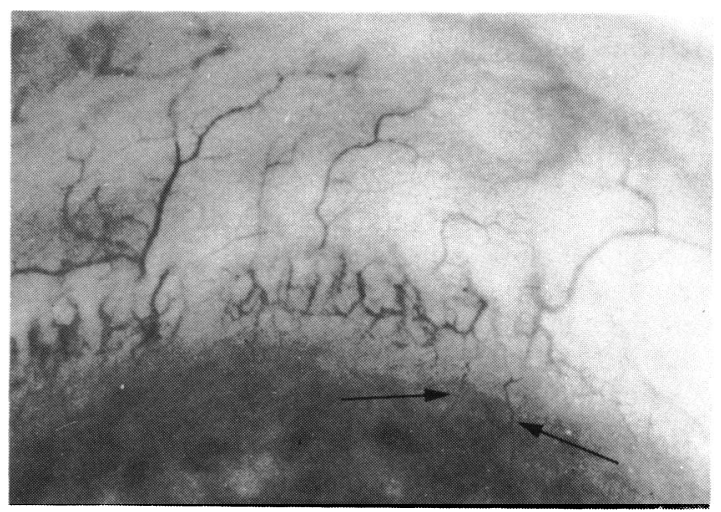

Fig. 3 Adult guinea-pig eye showing corneal vessels (arrows). 


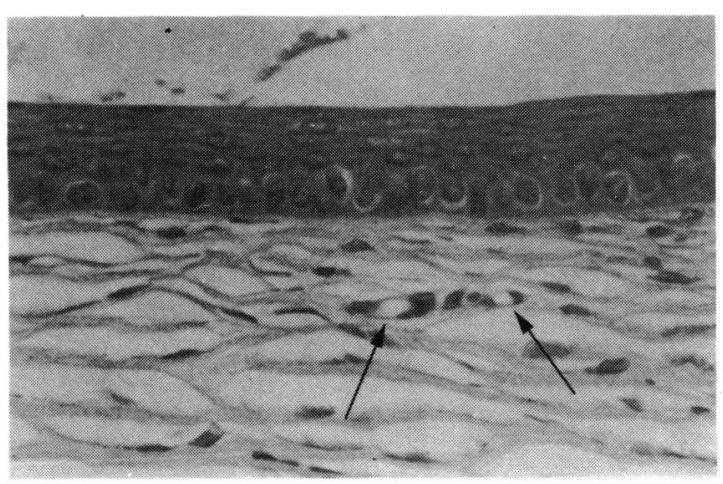

Fig. 4 Section of one-day-old guinea-pig eye cornea showing corneal vessels (arrows). (×334).

\section{Newborn animals}

Thirteen one-day-old guinea pigs were examined. Six animals had corneal blood vessels, grade 1 vessels in 3 animals and grade 2 vessels in the other 3 . No other clinical signs were observed.

Eight of these animals were examined at intervals during the first 90 days of life. Four had a mild hyperaemia or oedema in the upper palpebral conjunctiva on 2 or 3 occasions between days 10 and 60 . Protuberances in the palpebral conjunctiva were seen in one animal on day 14 and in a further 2 on day 18. On day 36 all 8 animals had protuberances, which were larger than on earlier occasions. There was no further increase in size during the period of observation. Grade 2 corneal vessels were seen in all 8 animals by day 25 .

\section{HISTOLOGICAL FINDINGS}

Fifty adult eyes, 18 eyes from newborn animals, and 21 fetal eyes were studied.

Blood vessels were found in the superficial corneal stroma of most eyes from adults, newborn animals,

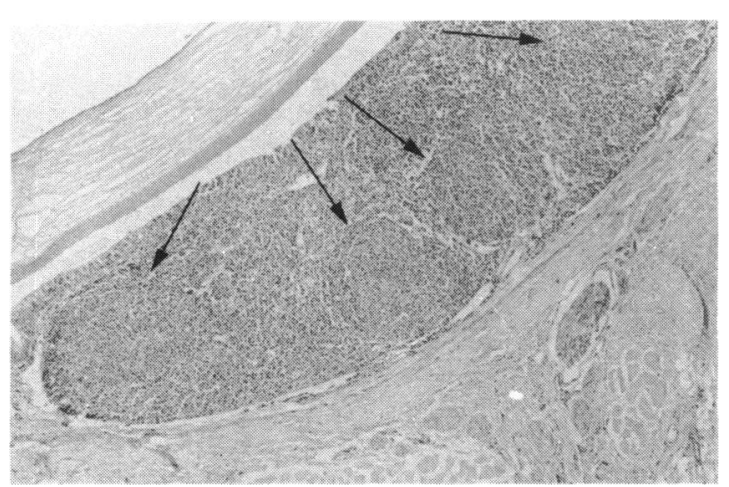

Fig. 5 Section of adult guinea-pig eye showing conjunctival lymphoid tissue with germinal centres (arrows). ( ×33).

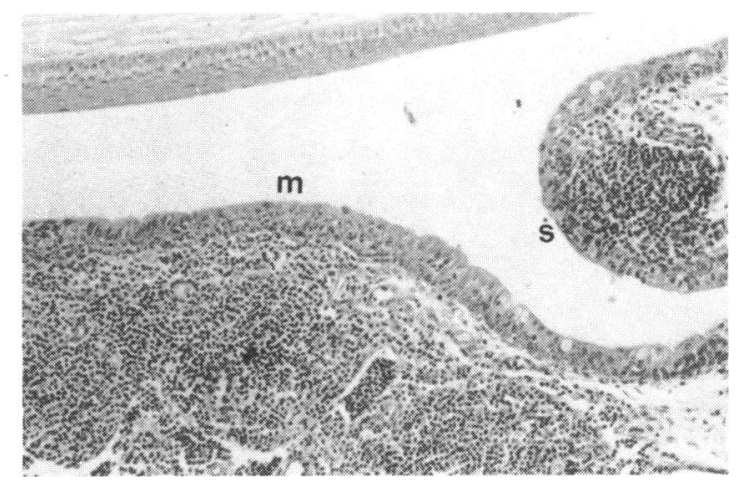

Fig. 6 Section of 4-day-old guinea-pig eye showing secondary mass of conjunctival lymphoid tissue under bulbar conjunctiva. Main tissue mass (m), secondary mass (s). (×84).

and also fetuses (Fig. 4). These corresponded in position to the corneal vessels described in clinical findings.

Masses of lymphoid tissue were present in the fornices in almost all the adult guinea-pig eyes, and these corresponded to the protuberances described in clinical findings. These masses varied widely in size and shape but always contained many plasma cells and were associated with blood vessels and lymphatic ducts. Most masses had at least one germinal centre, and some had multiple germinal centres (Fig. 5). Most animals had only one mass in each fornix, but a few had a secondary mass of lymphoid tissue under the bulbar epithelium. Examination of serial sections showed that in some cases these were 2 arms of a single mass and in other cases were 2 completely separate masses of tissue. There was often an appreciable infiltrate of lymphoid cells round the masses and under the adjacent conjunctiva. In some eyes the conjunctival epithelium above the lymphoid tissue was only one or 2 cells thick and was infiltrated with lymphoid cells.

In newborn animals lymphoid tissue was found in the fornices of all eyes. This varied from small groups of cells to large masses of tissue, and in one case there was a secondary mass under the bulbar conjunctiva (Fig. 6). The lymphoid tissue contained pyroninophilic cells resembling mature and immature plasma cells, and germinal centres were present in the larger masses.

In fetal animals similar accumulations of lymphoid cells with associated blood vessels and lymphatic ducts were observed. These accumulations varied widely in size. In some eyes cells extended under the bulbar epithelium (Fig. 7). Larger masses contained numerous cells with abundant pyroninophilic cytoplasm, resembling immature plasma cells, and the 


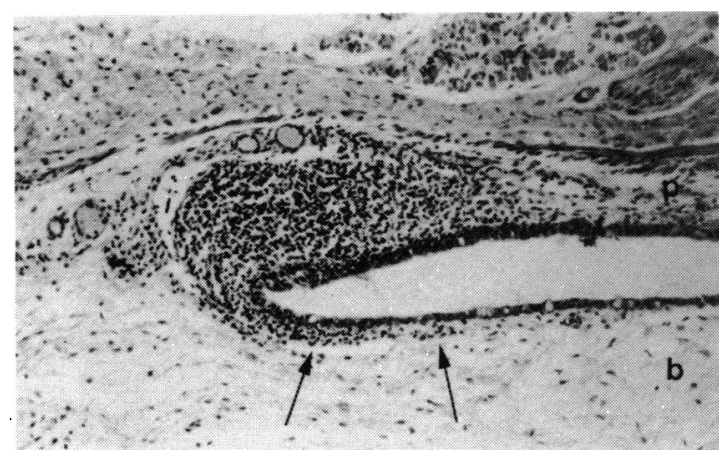

Fig. 7 Section of fetal guinea-pig eye showing conjunctival lymphoid tissue (arrows) extending under palpebral conjunctiva (p) and bulbar conjunctiva (b). $(\times 84)$.

overlying conjunctival epithelium was infiltrated with lymphoid cells (Fig. 8). Smaller masses contained some pyroninophilic cells and dividing cells.

Cell counts were carried out on 25 adult guinea-pig eyes. Lymphocyte counts at the various sites ranged from 0 to 12 cells per site, generally in the lower part of this range. Lymphocytic infiltration in the deeper zones beneath the counted areas was diffuse and sparse. No general polymorphonuclear cell infiltrate was observed, but cells were found at one or 2 sites in most eyes, and total counts ranged from one to 8 cells per eye. These cells were usually found in groups immediately under or in the conjunctival epithelium, and were often associated with one or 2 plasma cells. At the limbus a few lymphocytes and occasionally eosinophils were found around the blood vessels in the lamina propria of the conjunctiva.

In newborn animals cellular infiltration was less than in adults. Lymphocytic cells were much rarer. Accumulations of polymorphonuclear cells in the conjunctival epithelium, similar to those seen in adult eyes, were present (Fig. 9). A few cells were found round the limbal blood vessels. At 8 weeks there was an increase in the lymphocytic infiltration, reaching adult levels. In fetal eyes cell counts were similar to those of newborn eyes, but polymorphonuclear cells were rarely found.

Some of the adult eyes which had clinical signs of inflammation were examined histologically. There was no correlation between the presence of clinical signs and raised cell counts, particular cell types, numbers of germinal centres, or the size of the lymphoid masses.

\section{Discussion}

We have observed 2 features in normal female guinea-pig eyes which might otherwise be mistaken for pathological features. These are corneal blood

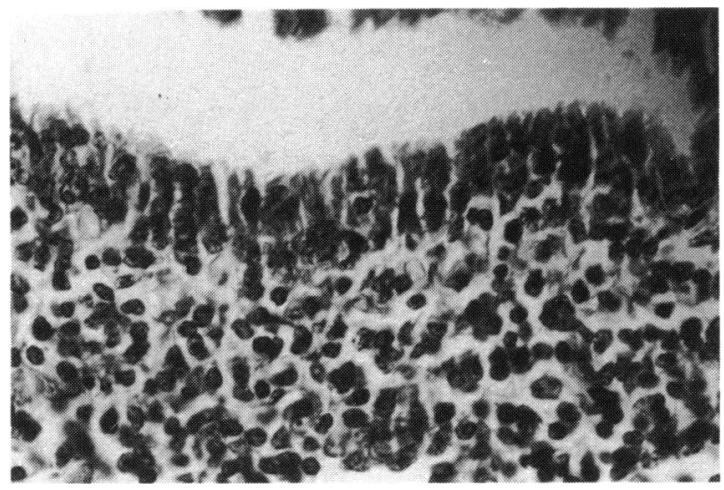

Fig. 8 Section of fetal guinea-pig eye showing infiltration of epithelium with mononuclear cells. $(\times 334)$.

vessels and masses of lymphoid tissue in the palpebral conjunctiva.

Corneal blood vessels could be seen with the aid of an operating microscope in newborn and adult eyes as well as in histological preparations of fetal eyes. We therefore consider that the presence of these blood vessels is a normal feature of the guinea-pig eye. It is likely therefore that some reports of neovascularisation following antigenic challenge or infection may be spurious. For example, corneal blood vessels were observed 6 hours after intracorneal injection of saline or antigen into normal eyes. ${ }^{2}$ While the authors realised that these vessels appeared much too quickly to be true neovascularisation, they were unable to see the vessels in normal eyes before injection.

The masses of lymphoid tissue in the fornices were present in fetal, newborn, and adult eyes. The occurrence of these accumulations of lymphoid cells in fetal eyes, together with blood vessels and lymphatic ducts, indicates that these masses are normal features of the guinea-pig eye. These masses become larger and more organised after birth, but it is

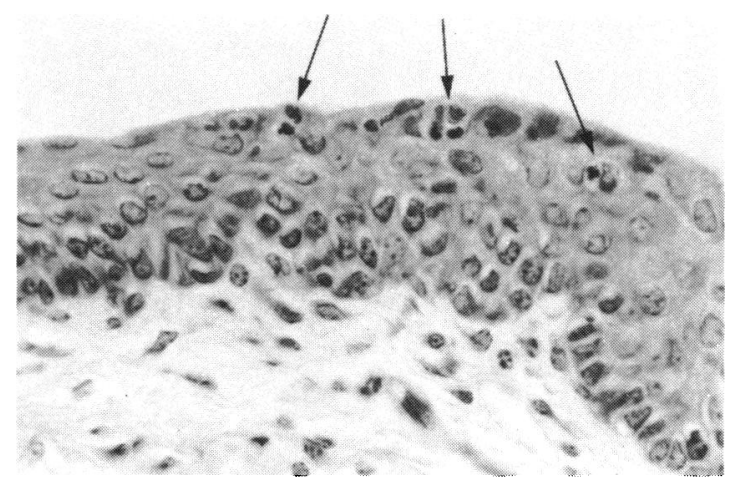

Fig. 9 Section of 3-day-old guinea-pig eye showing microscopic abscesses (arrows) in limbal epithelium. (×334). 
not clear to what extent the increase in size and complexity is a normal development or is due to antigenic stimulation. It has been reported that lymphoid masses are larger in conventionally raised guinea-pigs than in germ-free animals, which suggests that external stimuli influence growth of this lymphoid tissue. ${ }^{8}$ Conjunctival lymphoid tissue is also found in other species, including rats, mice, and rabbits. However, in guinea-pigs it is much more pronounced than in rats and mice $^{8}$ and appears before birth, whereas in rabbits it does not appear until after birth. ${ }^{9}$ The histological appearance of the conjunctival lymphoid tissue of both guinea-pigs and rabbits is similar to that of lymphoid tissue associated with other mucosal surfaces, such as the gut and bronchus. ${ }^{9}$ In this paper we have described corneal blood vessels and lymphoid tissue masses in female guinea-pigs, but we have also observed the same features in male guinea-pigs (unpublished observations).

The normal guinea-pig eye has an extremely low frequency of blinking and appears to be remarkably tolerant of foreign bodies showing little or no discomfort. It has corneal blood vessels and very large amounts of lymphoid tissue. In contrast, the human eye has a high frequency of blinking and a low tolerance of foreign bodies and does not normally have corneal blood vessels or conjunctival lymphoid tissue. It is not clear how these features of the outer eye are related, but the guinea-pig appears to have evolved a strategy for protecting the outer eye which is very different from that of humans.

We thank Professors Barrie R. Jones and John L. Turk for advice, Mary Lang, Eileen Wilson, and Maria Pink for technical assistance, and the Medical Research Council for financial support.

\section{References}

1 Holley SW. Corneal reactions of normal and of tuberculous guinea pigs to tuberculo-protein and tuberculo-phosphatide. Am J Pathol 1935; 11: $937-51$.

2 Schlossman S, Stetson CA. Vascularization of the cornea during delayed hypersensitivity reactions. J Immunol 1957; 79: 208-10.

3 Salvin SB, Gregg MB. The specificity of allergic reaction, IV. The cornea. Proc Soc Exp Biol Med 1961; 107: 478-83.

4 Meyers RL, Pettit TH. Corneal immune responses to herpes simplex virus antigens. J Immunol 1973; 110: 1575-90.

5 Friedlaender MH, Dvorak HF. Morphology of delayed-type hypersensitivity reactions in the guinea pig cornea. J Immunol 1977; 118: 1558-63.

6 Monnickendam MA, Darougar S, Treharne JD, Tilbury AM. Guinea-pig inclusion conjunctivitis as a model for the study of trachoma: clinical, microbiological, serological, and cytological studies of primary infection. BrJ Ophthalmol 1980; 64: 279-83.

7 Bitensky L. Histochemistry in Experimental Immunology. In: Weir DM, ed. Handbook of experimental immunology. Oxford and Edinburgh: Blackwell, 1967; 752-75.

8 McMaster PRB, Aronson SD, Bedford MJ. Mechanisms of the host response in the eye, IV. The anterior eye in germ-free animals. Arch Ophthalmol 1967; 77: 392-9.

9 Axelrod AJ, Chandler JW. Morphologic characteristics of conjunctival lymphoid tissue in the rabbit. In: Silverstein AM, O'Connor GR, eds. Immunology and immunopathology of the eye. New York, Paris, Barcelona, Milan, Mexico City, Rio de Janeiro: Masson, 1979: 292-301. 